\title{
Stocking Density and Feed Barrier Design Affect the Feeding and Social Behavior of Dairy Cattle
}

\author{
J. M. Huzzey, ${ }^{1}$ T. J. DeVries, P. Valois, and M. A. G. von Keyserlingk \\ Animal Welfare Program, Faculty of Land and Food Systems, \\ The University of British Columbia, Vancouver, Canada V6T 1 Z4
}

\begin{abstract}
The objectives of this study were to: 1) evaluate how stocking density at the feed bunk affects feeding and social behavior of dairy cows; and 2) determine if this effect is further influenced by the type of feed barrier used. Thirty-six lactating Holstein cows, allotted to 4 groups, were subjected to each of 4 stocking density treatments and 2 feed barrier treatments. Initially, 2 groups were assigned to a headlock barrier, and 2 groups to a post-and-rail barrier. Each group was then exposed to 4 stocking density treatments $(0.81,0.61$, 0.41 , and $0.21 \mathrm{~m} / \mathrm{cow}$, corresponding to $1.33,1.00,0.67$, and 0.33 headlocks/cow), in 4 successive 10 -d treatment periods. After these periods, the feed barriers were switched between groups and the 4 stocking density treatments were readministered. Time-lapse video was used to quantify feeding, standing, and aggressive behavior at the feed bunk. Daily feeding times were greater and duration of inactive standing in the feeding area was less when using a post-and-rail compared with a headlock feed barrier. Feeding time decreased and inactive standing increased for both barrier designs as stocking density increased at the feed bunk. Cows were displaced more often from the feeding area when the stocking density was increased, and this effect was greater for cows using the post-and-rail feed barrier. Cows ranked lower in the social hierarchy at the feed bunk were displaced more often when feeding at a postand-rail barrier, particularly at high stocking densities. Therefore, we recommend avoiding overstocking at the feed bunk to increase feeding activity and reduce competition. Use of a barrier that provides some physical separation between adjacent cows, such as a headlock feed barrier, can be used to further reduce competition at the feed bunk.
\end{abstract}

Key words: feed barrier, stocking density, feeding behavior, social behavior

Received June 27, 2005.

Accepted August 24, 2005.

${ }^{1}$ Corresponding author: jmhuzzey@interchange.ubc.ca

\section{INTRODUCTION}

One of the primary objectives of dairy producers is to promote DMI to support milk production. The DMI of group-housed lactating dairy cows is affected by feeding behavior, which in turn, is influenced by factors such as the environment and herd management. Amount of available feeding space has been shown to influence the level of competition at the feed bunk (DeVries et al., 2004). Furthermore, it has been suggested that competition at the feed bunk can affect feeding behavior and DMI (Friend et al., 1977; Olofsson, 1999; Grant and Albright, 2001). Current industry recommendations typically advise that each cow have approximately 0.6 $\mathrm{m}$ of linear feed bunk space to ensure that all cows can feed simultaneously (Grant and Albright, 2001). Some have suggested that this recommendation is overly cautious, given that cows have had similar feed intake and milk production with space allotments much less than the recommended level (Friend and Polan, 1974, Friend et al., 1977; Menzi and Chase, 1994). In contrast, others have noted that increased competition at high stocking densities can limit the ability of some cows to gain access to the feed bunk at desired feeding times (DeVries et al., 2004).

The physical barrier separating the cows and the area where the feed is delivered also has the potential to affect feeding behavior. A barrier design that provides some sort of separation between cows (e.g., headlocks) may reduce competition by making it more difficult for cows to displace each other from the feed bunk. Unfortunately, little research substantiates this idea. Previous researchers (Batchelder, 2000; Brouk et al., 2003) compared headlocks with more open feed barriers, like the post-and-rail barrier, but reported variable results, used limited treatment replicates, and did not address the effects of barrier design on the feeding and social behavior of the cows. A more recent study (Endres et al., 2005) compared the effects of using a headlock and post-and-rail feed barrier on the feeding and social behavior of lactating dairy cows. Those researchers reported that headlock barriers reduced the frequency of aggressive interactions at the feed bunk, and allowed cows more equal access to feed during peak feeding 
periods. In that study (Endres et al., 2005), cows were kept at a $100 \%$ stocking density (relative to the $0.6 \mathrm{~m} /$ cow standard) at the feed bunk.

Given that crowding at the feed bunk can increase competition, which can negatively affect feeding behavior, we hypothesized that a feed barrier that reduces competitive behavior at the feed bunk may reduce the negative effects of crowding. Therefore, the objectives of our study were to: 1) evaluate how stocking density at the feed bunk affects the feeding and social behavior of dairy cows, and 2) determine if the effects of stocking density are further influenced by the type of feed barrier design used.

\section{MATERIALS AND METHODS}

\section{Cows, Housing, and Diet}

Sixteen primiparous and 20 multiparous (parity $=$ $3.5 \pm 0.3$; mean $\pm \mathrm{SD}$ ) Holstein cows were housed in a free-stall barn at The University of British Columbia Dairy Education and Research Center (Agassiz, BC, Canada). All cows were cared for according to the guidelines outlined by the Canadian Council on Animal Care (1993). Cows were allotted to 4 groups of 9 cows each, and balanced across groups for projected 305-d milk production $(11,186 \pm 2,057 \mathrm{~kg})$, DIM at the beginning of the experiment ( $87 \pm 18 \mathrm{DIM})$, and parity $(2.4 \pm 1.6)$. The groups were housed in 4 adjacent pens, and had access to 9 deep-bedded sand stalls. Cows were fed a TMR consisting of $21.5 \%$ grass silage, $14.6 \%$ corn silage, $5.6 \%$ alfalfa hay, $3.5 \%$ third-cut grass hay, $32.3 \%$ energy blend, and $22.5 \%$ concentrate mash on a DM basis $(\mathrm{DM}=46.9 \%, \mathrm{CP}=18.7 \%, \mathrm{ADF}=18.5 \%$, and $\mathrm{NDF}=$ $33.9 \%)$. Fresh feed was provided twice daily at approximately 0530 and $1530 \mathrm{~h}$. Feed was pushed up daily at approximately 1100,1800 , and 2230 h. Cows had ad libitum access to water and were milked twice daily at approximately 0500 and $1700 \mathrm{~h}$.

Samples of the TMR were collected on $\mathrm{d} 1,4$, and 8 of each treatment period. The DM content of the samples was determined by drying in a hot air oven at $60^{\circ} \mathrm{C}$ for $3 \mathrm{~d}$. The DMI for each group for each day on treatment was recorded by subtracting the DM weight of the orts from the DM weight of the fresh feed. This study was designed to test predictions concerning feeding and competitive behavior. Differences in DMI and milk production were not tested because we were unable to accurately measure individual DMI and treatment periods were too short to detect differences in milk yield. During the course of the study, DMI of the cows averaged $23.9 \pm 2.5$ (mean $\pm \mathrm{SD}$ ) $\mathrm{kg} / \mathrm{d}$, and the cows produced $40.3 \pm 8.5 \mathrm{~kg}$ of milk per day.

\section{Experimental Treatments and Design}

Each of the 4 groups was exposed to 2 types of feed barriers: headlock and post-and-rail (Figure 1). Within each barrier treatment, 4 stocking densities were tested: $0.81,0.61,0.41$, and $0.21 \mathrm{~m}$ of linear bunk space per cow, corresponding to $1.33,1.00,0.67$, and 0.33 headlocks per cow. Initially, 2 groups had a post-andrail barrier whereas the other 2 groups had a headlock barrier. Each group was tested with each stocking density in 4 successive 10-d treatment periods, with density applied to each group using a Latin square. For the first $2 \mathrm{~d}$ of each $10-\mathrm{d}$ period, cows were returned to the baseline density $(0.61 \mathrm{~m}$ per cow or 1 headlock per cow) to provide a recovery period from the previous treatment. This was done to minimize the possibility of treatment carryover to the next period. After this 2$\mathrm{d}$ baseline period, the respective stocking density treatment of each group was administered for the remaining $8 \mathrm{~d}$ of the period. Once each group had received each of the 4 stocking density treatments with their respective feed barrier design, the barriers were switched between groups. Stocking density treatments were assigned to groups in the same manner as in the first half of the experiment. Wooden partitions were placed within the feed bunk between groups to ensure that cows could not consume food from adjacent feed bunks. For both barrier designs, feed bunk space was adjusted by placing concrete partitions $(60 \times 60 \times 90 \mathrm{~cm})$ at different locations along the feed bunk, and feed was placed only within the space created by the partitions.

\section{Monitoring Behavior}

Feeding, standing, and aggressive behaviors at the feed bunk were recorded during the last $4 \mathrm{~d}$ of each stocking density treatment period. All behaviors were continuously monitored using video cameras (CCTV camera, model no. WV-BP330; Panasonic, Osaka, Japan) fitted with an F1.4/2.5 to $6 \mathrm{~mm}$ lens. Cameras were connected to a video multiplexer (Panasonic Video Multiplexer WJ-FS416) and a time-lapse videocassette recorder (Panasonic Time Lapse Video Cassette Recorder AG-6540). A camera was placed $6 \mathrm{~m}$ above the feed bunk of each group, and was positioned so that the entire feed bunk length as well as the entire feeding area of each pen was visible. Red lights $(100 \mathrm{~W})$, hung adjacent to the cameras, were used to facilitate video recording at night. Cows were identified on their backs with unique alphanumeric symbols made with hair dye.

Measuring Feeding and Standing Behavior. Feeding behavior of individual cows, as well as the duration of inactive standing in the feed area, was scored from video recordings using 10-min time sampling (Endres et al., 2005). For each scan, a cow was considered 
$\mathbf{A}$

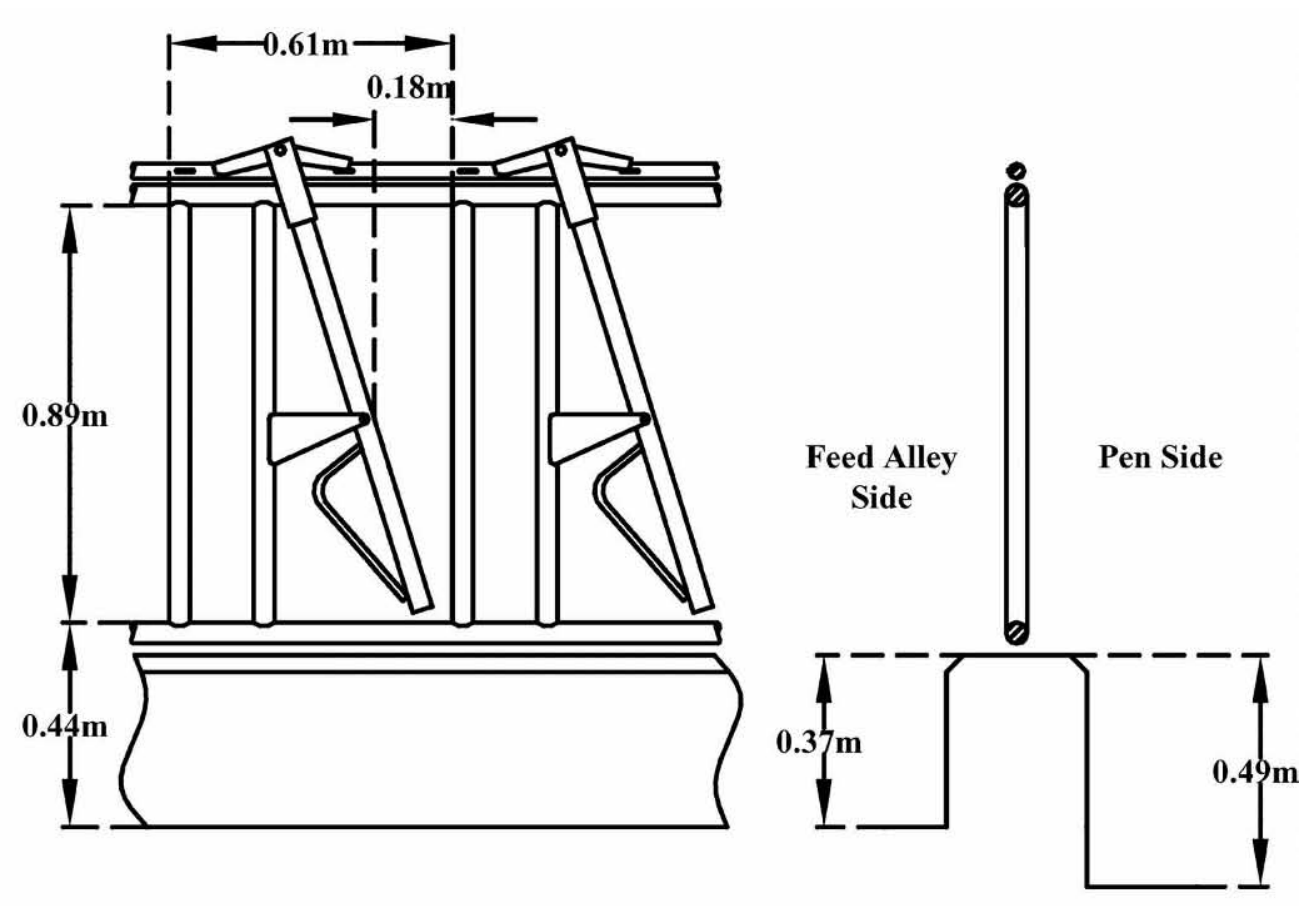

B

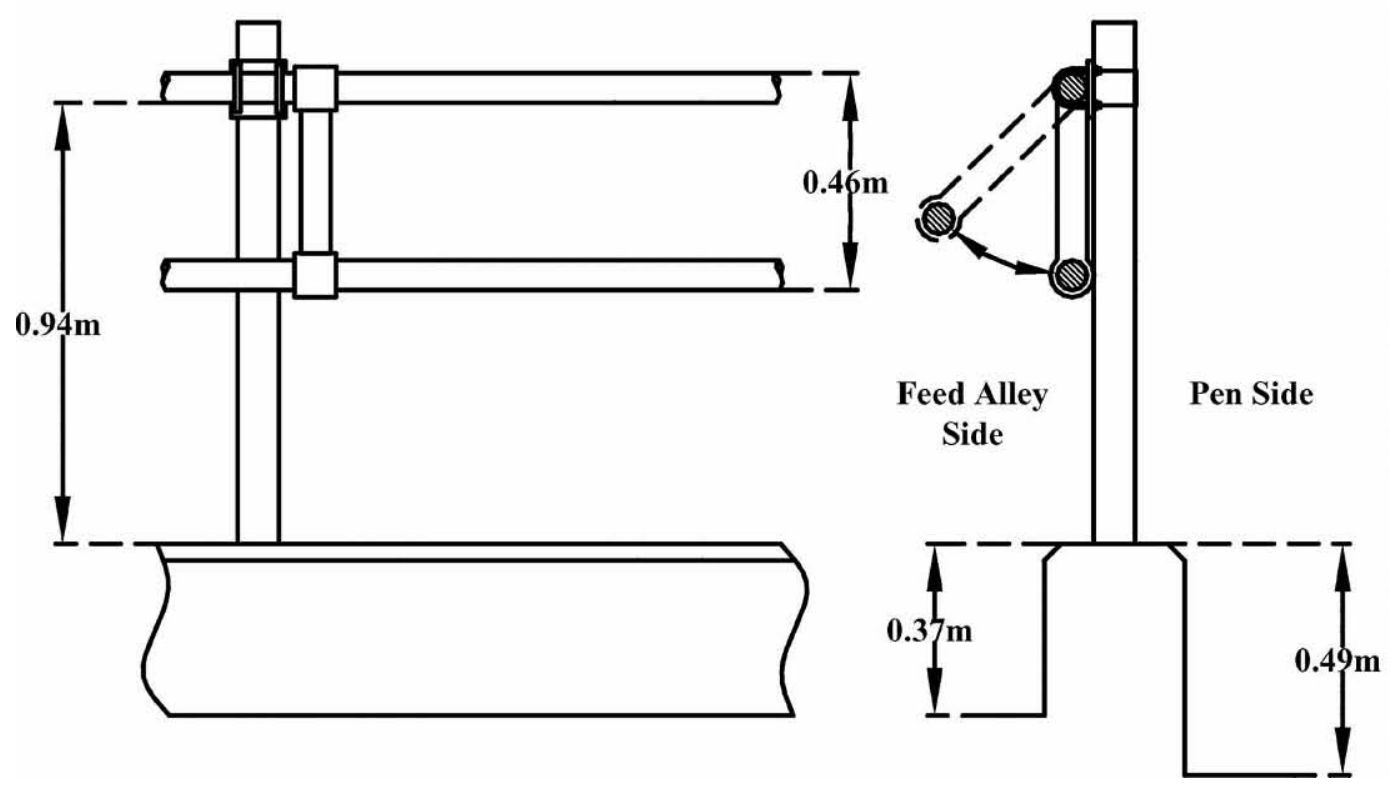

Figure 1. Front and cross-sectional views of a portion of the headlock (A) and post-and-rail (B) feed barriers used in this study.

to be feeding when its neck collar was visible beyond the top rail of either feed barrier on the feed alley side of the pen. A cow was recorded as inactively standing when it had all 4 feet within the pen alley closest to the feed bunk and was not feeding. Total time spent feeding ( $\mathrm{min} / \mathrm{d}$ ) and inactively standing ( $\mathrm{min} / \mathrm{d}$ ) was calculated by multiplying by 10 the number of times a cow was observed to be feeding/inactively standing. In addition, to detect changes in daily pattern of feed bunk attendance, these scans were used to calculate the percentages of the cows feeding and inactively standing during the course of a 24-h day.

Measuring Aggressive Behavior. The number of displacements per cow was used to measure the compet- 
itive behavior of cows at the feed bunk. A displacement was noted when a cow's head (actor) came in contact with a cow that was feeding (reactor), resulting in the reactor withdrawing its head from the feed bunk. In addition to using the number of displacements as a dependent variable, these observations were used to calculate an index of success in competitive interactions for each individual cow. An index of success was calculated for each cow for each treatment period (i.e., for each feed barrier and stocking density combination). The index of success (Mendl et al., 1992; DeVries et al., 2004) was calculated as follows:

$\begin{aligned} & \text { number of cows that an individual is able to displace } \\ & \text { number of cows that an individual is able to displace }\end{aligned} \times 100 \%$

\section{Statistical Analyses}

For the analysis of feeding behavior, inactive standing time, and displacements from the feed bunk, the experimental unit was the pen, with measures from multiple days and cows averaged to create one observation per pen per treatment. Treatment effects were tested using a repeated-measures mixed model. Compound symmetry was selected as the covariance structure based on best fit using the Bayesian information criteria in the PROC MIXED procedure (SAS Institute, 1999). Subsequent analyses were performed with PROC GLM, which uses the compound symmetry structure as a default and allowed us to model the stocking density as a continuous variable. The model included group ( $3 \mathrm{df}$ ), period ( $7 \mathrm{df}$ ), feed barrier ( $1 \mathrm{df})$, linear effect of stocking density ( $1 \mathrm{df}$ ), quadratic effect of stocking density ( $1 \mathrm{df}$ ), interactions between feed barrier, linear and quadratic effects ( $1 \mathrm{df}$ each), and the residual error (16 df).

To test the hypothesis that socially subordinate cows would be most affected by increased crowding, the effects of stocking density and barrier design on displacements from the feed bunk also were evaluated with cow as the observational unit and each cow's index of success as a covariate. The model included terms for index of success ( $1 \mathrm{df})$, cow (35 df), period ( $7 \mathrm{df})$, feed barrier (1 df), linear and quadratic effects of stocking density ( $1 \mathrm{df}$ each), various first-order interactions, and the residual error ( $238 \mathrm{df})$.

\section{RESULTS}

\section{Feeding Behavior}

Daily feeding times of cows decreased with increased stocking density in a curvilinear manner (Figure 2; linear effect: $P<0.001$; quadratic effect: $P=0.006$ ). Daily

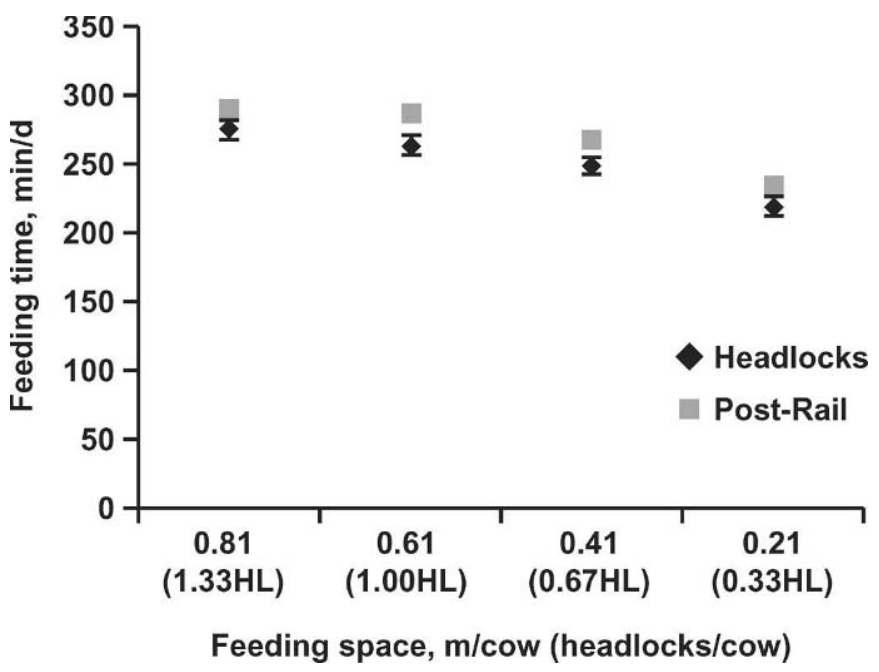

Figure 2. Daily feeding time per cow (mean $\pm \mathrm{SE}$ ) at 4 different stocking density treatments when provided either a headlock (HL) or a post-and-rail feed barrier. Data were averaged for the last $4 \mathrm{~d}$ of each treatment of 4 groups, each containing 9 cows.

feeding time was further reduced $(P<0.001)$ when cows used the headlock barrier compared with the post-andrail barrier (Figure 2). Treatment effects of stocking density were most pronounced during times of peak feeding activity. Periods of peak feeding activity were observed to be within 60 min following the delivery of fresh feed (Figure 3). During these periods, more cows were at the post-and-rail barrier than at the headlock barrier, and the percentage of cows feeding decreased with increasing stocking density in a quadratic manner (Table 1).

\section{Standing Behavior}

As stocking density at the feed bunk increased, a linear increase $(P<0.001)$ in the time cows spent inactively standing in the feeding area was detected (Figure 4). In addition, inactive standing time at the feed bunk was further increased $(P<0.001)$ when cows were fed at a headlock feed barrier compared with a post-andrail feed barrier. Similar to feeding behavior, treatment effects of stocking density on the inactive standing times of cows were most pronounced during the times of peak feeding activity. During these periods, the percentage of cows inactively standing in the feeding area increased $(P<0.001)$ quadratically with increasing stocking density (Table 1).

\section{Aggressive Behavior}

The number of times cows were displaced from the feeding area increased in a curvilinear manner as stock- 


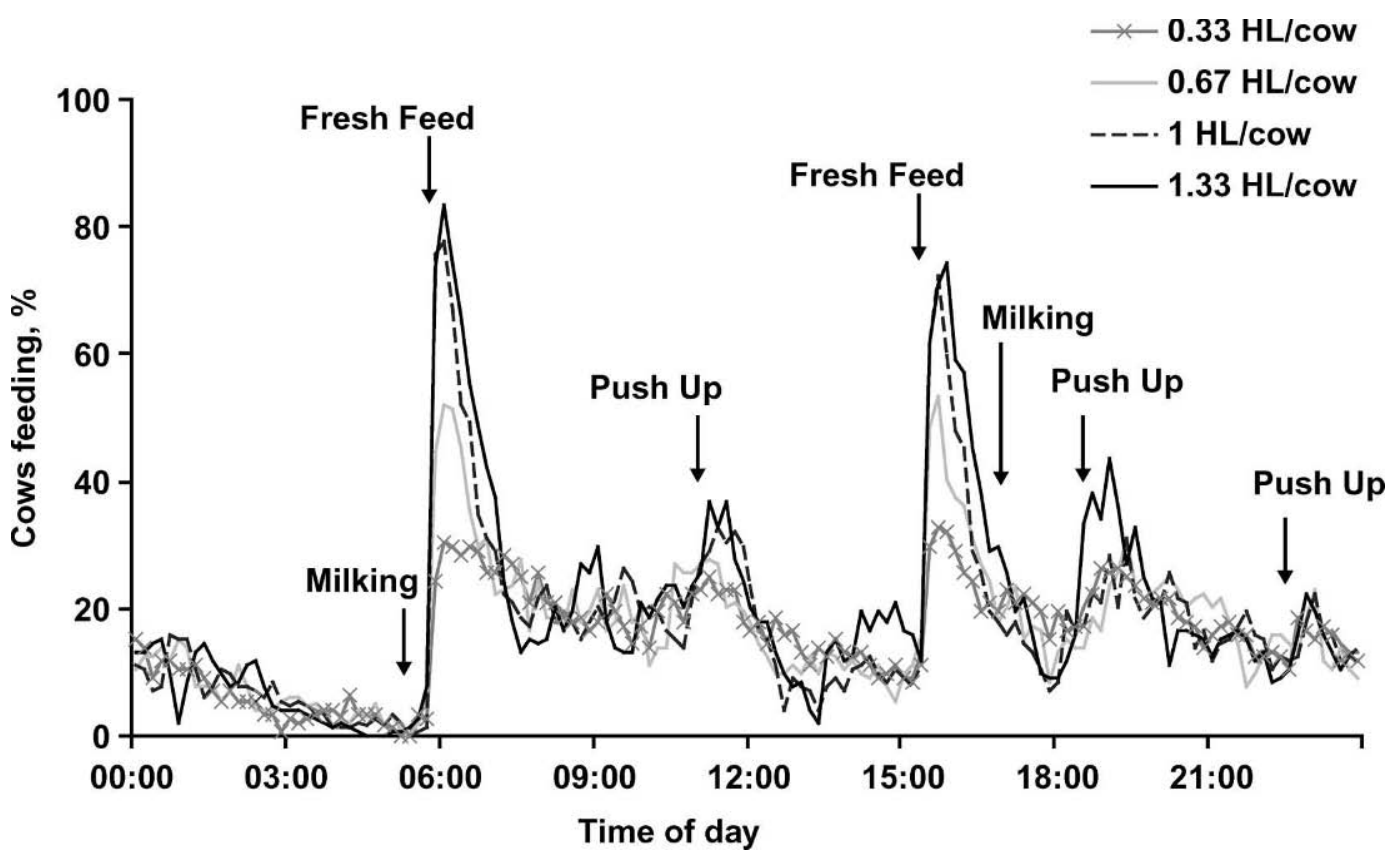

Figure 3. Percentages of cows at the headlock feed barrier during a 24-h period (percentages for each 10-min interval during the day) at 4 different stocking density treatments: 1) 1.33 headlocks (HL)/cow, 2) $1 \mathrm{HL} / \mathrm{cow}, 3) 0.67 \mathrm{HL} / \mathrm{cow}$, and 4) $0.33 \mathrm{HL} / \mathrm{cow}$. Data were averaged for the last $4 \mathrm{~d}$ of each treatment of 4 groups, each containing 9 cows. Because daily pattern of bunk attendance was similar for the postand-rail barrier, data are not shown.

ing density increased (linear effect: $P<0.001$; quadratic effect: $P=0.003)$, and was greater $(P=0.007)$ when using the post-and-rail vs. the headlock feed barrier (Figure 5). The cow-based analysis, considering the cow's index of success and the relevant interactions, revealed an index of success $\times$ feed barrier $\times$ quadratic effect of stocking density interaction $(P=0.018)$. This interaction demonstrated that cows with lower indices of success were displaced more often with the post-andrail barrier design, particularly at high stocking densities.

\section{DISCUSSION}

This study is the first to examine how stocking density at the feed bunk and feed barrier design interact to affect the feeding and competitive behavior of grouphoused dairy cattle. Feeding time decreased for both barrier designs in an accelerating fashion with increasing density at the feed bunk, showing that progressive increases in stocking density resulted in larger decreases in feeding time. Others have shown that cows spend less time feeding when they have less available bunk space (Olofsson, 1999; DeVries et al., 2004); however, these studies were not designed to test multiple levels of feeding space. Similar to the present study, Friend et al. (1977) tested several different stocking densities. They only observed, however, a significant decline in feeding time and DMI at the smallest space allowance per cow ( $0.1 \mathrm{~m}$ of linear bunk space per cow). Unfortunately, that study used a small number of cows and did not replicate their treatments. Therefore, their

Table 1. Percentage of cows per group feeding and inactively standing during peak feeding activity (60 min following the delivery of fresh feed) at 4 different stocking density treatments, when exposed to either a headlock or a post-and-rail feed barrier

\begin{tabular}{|c|c|c|c|c|c|c|c|c|c|c|c|c|}
\hline & \multicolumn{4}{|c|}{ Headlock (headlocks/cow) } & \multicolumn{4}{|c|}{ Post-and-rail (m/cow) } & \multirow[b]{2}{*}{ SE } & \multicolumn{3}{|c|}{$P$-value } \\
\hline & 1.33 & 1.00 & 0.67 & 0.33 & 0.81 & 0.61 & 0.41 & 0.21 & & Barrier $^{1}$ & $\mathrm{~L}_{\mathrm{SD}}^{2}$ & $\mathrm{QSD}^{3}$ \\
\hline Cows feeding, ${ }^{4} \%$ & 61.3 & 54.6 & 43.9 & 28.5 & 61.1 & 63.2 & 48.0 & 33.8 & 2.4 & 0.01 & $<0.001$ & 0.002 \\
\hline
\end{tabular}

${ }^{1}$ Effect of feed barrier design.

${ }^{2}$ Linear effect of stocking density.

${ }^{3}$ Quadratic effect of stocking density.

${ }^{4}$ Data were averaged for the last $4 \mathrm{~d}$ of each treatment of 4 groups, each containing 9 cows. 


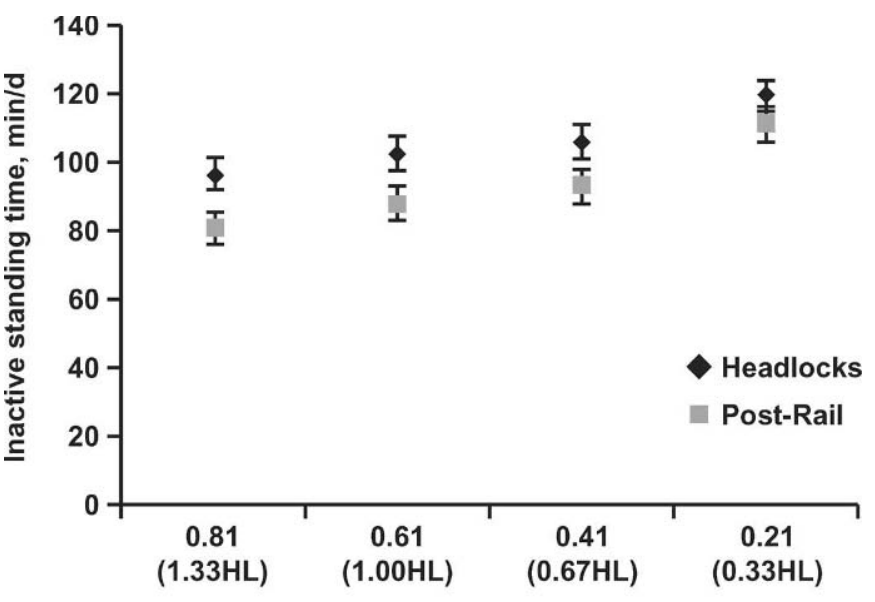

Feeding space, $\mathrm{m} / \mathrm{cow}$ (headlocks/cow)

Figure 4. Daily time spent inactively standing in the feeding area per cow (mean $\pm \mathrm{SE}$ ) at 4 different stocking density treatments when provided either a headlock (HL) or a post-and-rail feed barrier. Data were averaged for the last $4 \mathrm{~d}$ of each treatment of 4 groups, each containing 9 cows.

conclusions must be regarded with caution. DeVries et al. (2004) reported that when feeding space was doubled from 0.5 to $1.0 \mathrm{~m}$ per cow, daily feeding time was increased by $14 \%$. Even though $0.6 \mathrm{~m}$ of linear bunk space has traditionally been regarded as adequate (Grant and Albright, 2001), results of the current study and those of DeVries et al. (2004) indicate that feeding time would likely increase if cows were provided more than $0.6 \mathrm{~m}$ of feed bunk space per cow.

Results of the current study also indicate that cows spend more time feeding when using a post-and-rail vs.

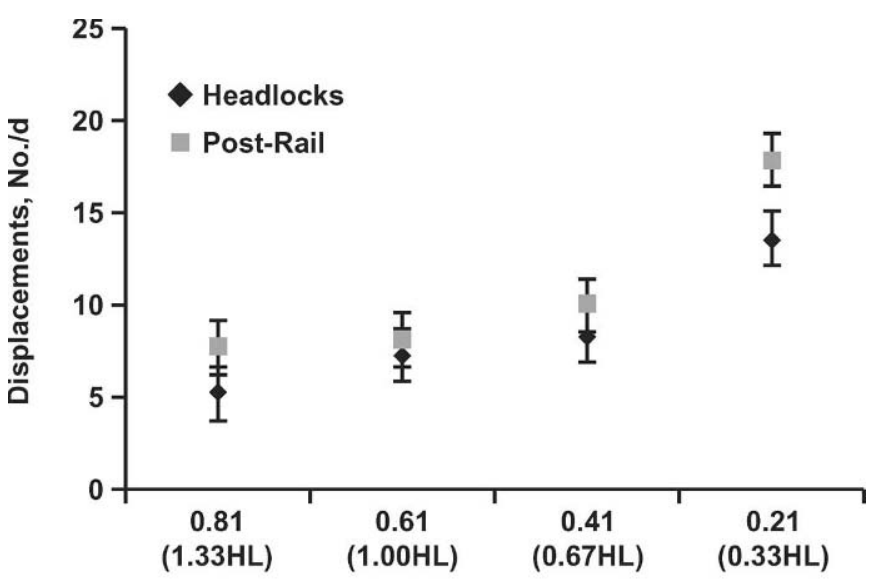

Feeding space, $\mathrm{m} / \mathrm{cow}$ (headlocks/cow)

Figure 5. Daily number of displacements per cow (Mean \pm SE) at 4 different stocking density treatments when provided either a headlock (HL) or post-and-rail feed barrier. Data were averaged for the last $4 \mathrm{~d}$ of each treatment of 4 groups, each containing 9 cows. a headlock feed barrier. The post-and-rail feed barrier provides less of a physical barrier between the cows and the feed and between adjacent cows, perhaps making feeding more comfortable for the cows. Alternatively, cows may have developed a learned aversion to the headlocks. Such a feed barrier is often used to restrain cows during uncomfortable procedures such as herd health examinations and artificial insemination. Thus, cows may be reluctant to cross this barrier to access feed. In a recent study (Endres et al., 2005), no difference was reported in the daily feeding time of cows using a post-and-rail compared with a headlock feed barrier, but they found that during periods of peak feeding activity (observed during $90 \mathrm{~min}$ following fresh feed delivery), cows spent $9 \%$ more time feeding when fed using the post-and-rail design. Likewise, in our study, the most dramatic differences in feeding activity occurred during periods of peak feeding activity (observed during $60 \mathrm{~min}$ following fresh feed delivery). During this period, more cows were present at the bunk when a post-and-rail barrier was provided.

Others (Batchelder, 2000; Brouk et al., 2003) compared the use of headlocks to the more open post-andrail design, but limited their focus to the effects on DMI rather than on feeding or social behavior. Batchelder (2000) compared these 2 feed barrier designs at 2 different stocking densities ( 0.72 and $0.55 \mathrm{~m}$ of linear bunk space per cow), and found that DMI was 3 to $6 \%$ greater when using the post-and-rail barrier design. In contrast, Brouk et al. (2003) found no difference in DMI between the 2 barriers. In both studies, limited treatment replicates were used, and thus the results should be regarded with caution.

In the current study, cows spent more time standing in the feeding area while not feeding (inactive standing) when stocking density was increased. Olofsson (1999) demonstrated that when cows were forced to alter their feeding behavior, due to changes in space allowance at the feed bunk, they also altered other aspects of their behavioral time budget. Similar to our findings, this researcher reported that although cows decreased their feeding time when overstocked, they compensated by increasing their inactive standing time. More work is warranted to determine the exact relationship between stocking density, standing behavior, and hoof health. Cows exhibiting longer standing times, especially on hard surfaces, are thought to be at a higher risk of developing hoof and leg injuries (Greenough and Vermunt, 1991).

In the current study, the greatest differences in inactive standing occurred during periods of peak feeding activity, likely because the feed bunk was largely occupied during these periods and cows were forced to wait in the feeding area until space became available. This 
observation complements the conclusion of DeVries and von Keyserlingk (2005), in which they stated that all cows are motivated to access the feed bunk upon the delivery of fresh feed. When feed bunk space is inadequate, some cows may be prevented access to the feed bunk at the time of fresh feed delivery and consequently may be forced to shift their feeding time. Previous work has indicated that cows will sort a TMR, preferentially consuming the grain components and leaving the forage (Leonardi and Armentano, 2003). Because of feed sorting, feed quality declines throughout the day (DeVries et al., 2005). Thus, cows that are forced to delay their feeding time due to overcrowding at the feed bunk may consume a poorer quality diet.

We found that reduced space availability increased the number of aggressive interactions, particularly at the $0.21 \mathrm{~m} / \mathrm{cow}$ stocking density. The average number of times a cow was displaced from the feed bunk when provided $0.81 \mathrm{~m}$ of feed bunk space per cow was only $41 \%$ of that detected for the $0.21 \mathrm{~m} /$ cow treatment. Similarly, DeVries et al. (2004) reported that the average number of times a cow displaced another from the feed alley, during the 90 -min peak feeding period, when provided $1.0 \mathrm{~m}$ of feed alley space per cow, was only $43 \%$ of that observed during that same time period for the $0.5 \mathrm{~m} / \mathrm{cow}$ treatment. Olofsson (1999) also reported an increased number of displacements when the number of cows per feeding station increased from 1 to 4 . To date, little is known about health and production effects on cows because of this competitive behavior. In a preliminary study (Leonard et al., 1998), it was suggested that cows that engaged in a high number of aggressive interactions at the feed bunk had more severe clawhorn lesion scores than those that did not engage in such encounters. Further, during the first few weeks after calving, cows may be particularly vulnerable to disease when overstocking leads to increased competition (Grant and Albright, 1995). To date, no researchers have determined whether a competitive social environment at the feed bunk increases susceptibility to peripartum diseases. Future studies concerning stocking density at the feed bunk should be designed to examine the long-term effects of overstocking and competition on measures such as DMI, milk production, claw health, and disease incidence.

The headlock feed barrier seemed to offer some protection against aggressive displacements, evidenced by fewer displacements being observed at this barrier than at the post-and-rail barrier. It has been suggested that cows may feel more protected when a physical separation exists between them at a feed bunk (Konggaard, 1983). Bouissou (1970) examined this idea by comparing the effects of different types of physical barriers on the feeding times of hungry cows positioned side-by- side at the feed bunk. This researcher found that those barriers that provided complete separation between the heads of adjacent cows (i.e., the barrier between cows extended out into the feed bunk) allowed subordinates better access to feed. This effect of barrier design may be because cattle often displace one another while feeding by swinging and butting with the head. A physical barrier between cows, such as the headlock barrier, which provides a division between the necks of the cows at the feed bunk, may reduce the frequency of such displacements by preventing this lateral swinging motion.

In their recent review, Cook et al. (2004) argued that the majority of studies have failed to consider how reduced feeding space affects individual cows. Further, they suggested that subordinate cows might be more affected by greater stocking densities. Our results address this gap in the literature, and indicate that subordinate cows are displaced most often at high stocking densities, particularly when using a post-and-rail barrier.

\section{CONCLUSIONS}

For both the post-and-rail and headlock barriers, increasing the stocking density resulted in reduced feeding times and increased inactive standing times in the feeding area. These changes were most obvious during the times of peak feeding activity (60 min following the delivery of fresh feed). Cows accessing feed via the postand-rail barrier spent more time eating and less time inactively standing in the feeding area. In contrast, cows were less likely to be displaced from the feed bunk when using the headlock barrier, suggesting that headlocks provide some protection against competitive interactions at the feed bunk. In addition, increasing the stocking density at the feed bunk increased the frequency at which cows were displaced, particularly for subordinate cows using the post-and-rail feed barrier. Therefore, we recommend avoiding overstocking at the feed bunk to increase feeding activity and reduce competition. Use of a barrier that provides some physical separation between adjacent cows, such as a headlock feed barrier, can be used to further reduce competition at the feed bunk.

\section{ACKNOWLEDGMENTS}

We thank the staff of The University of British Columbia Dairy Education and Research Centre and the University's Animal Welfare Program. In particular, we thank Dan Weary for his comments on the statistical design and analyses, and Sebastian Unden for his help with the feed barrier diagrams. This project was funded 
by the Natural Sciences and Engineering Research Council of Canada, through the Industrial Research Chair in Animal Welfare, and by contributions from Dairy Farmers of Canada, the British Columbia Dairy Foundation, the British Columbia SPCA, members of the British Columbia Veterinary Medical Association, and many other donors listed on the Animal Welfare website at http://www.agsci.ubc.ca/animalwelfare.

\section{REFERENCES}

Batchelder, T. L. 2000. The impact of head gates and overcrowding on production and behavior patterns of lactating dairy cows. Pages 325-330 in Dairy Housing and Equipment Systems. Managing and Planning for Profitability. NRAES-129. NRAES, Ithaca, NY.

Bouissou, M.-F. 1970. Role du contact physique dans la manifestation des relations hierarchiques chez les bovines. Consequences pratiques. Ann. Zootech. 19:279-285.

Brouk, M. J., J. F. Smith, and J. P. Harner III. 2003. Effect of feedline barrier on feed intake and milk production of dairy cattle. Pages 192-195 in Proc. 5th Int. Dairy Housing Conf. K. A. Janni, ed. Am. Soc. Agric. Eng., St. Joseph, MI.

Canadian Council on Animal Care. 1993. Guide to the care and use of experimental animals. Vol. 1. E. D. Olfert, B. M. Cross, and A. A. McWilliam, ed. CCAC, Ottawa, Canada.

Cook, N. B., K. V. Nordlund, and G. R. Oetzel. 2004. Environmental influences on claw horn lesions associated with laminitis and subacute ruminal acidosis in dairy cows. J. Dairy Sci. 87(E. Suppl.):E36-E46.

DeVries, T. J., and M. A. G. von Keyserlingk. 2005. Time of fresh feed delivery affects the feeding and lying patterns of dairy cows. J. Dairy Sci. 88:625-631.

DeVries, T. J., M. A. G. von Keyserlingk, and K. A. Beauchemin 2005. Frequency of feed delivery affects the behavior of lactating dairy cows. J. Dairy Sci. 88:3553-3562.

DeVries, T. J., M. A. G. von Keyserlingk, and D. M. Weary. 2004. Effect of feeding space on the inter-cow distance, aggression, and feeding behavior of free-stall housed lactating dairy cows. J. Dairy Sci. 87:1432-1438.

Endres, M. I., T. J. DeVries, M. A. G. von Keyserlingk, and D. M. Weary. 2005. Effect of feed barrier design on the behavior of loosehoused lactating dairy cows. J. Dairy Sci. 88:2377-2380.

Friend, T. H., and C. E. Polan. 1974. Social rank, feeding behavior, and free stall utilization by dairy cattle. J. Dairy Sci. 57:12141222 .

Friend, T. H., C. E. Polan, and M. L. McGilliard. 1977. Free stall and feed bunk requirements relative to behavior, production, and individual feed intake in dairy cows. J. Dairy Sci. 60:108-118.

Grant, R. J., and J. L. Albright. 1995. Feeding behavior and management factors during the transition period in dairy cattle. J. Anim. Sci. 73:2791-2803.

Grant, R. J., and J. L. Albright. 2001. Effect of animal grouping on feeding behavior and intake of dairy cattle. J. Dairy Sci. 84(E. Suppl.):E156-E163.

Greenough, P. R., and J. J. Vermunt. 1991. Evaluation of subclinical laminitis in a dairy herd and observations on associated nutritional and management factors. Vet. Rec. 128:11-17.

Konggaard, S. P. 1983. Feeding conditions in relation to welfare for dairy cows in loose-housing systems. Pages 272-280 in Farm Animal Housing and Welfare. S. H. Baxter, M. R. Baxter, and J. A. D. MacCormack, ed. Martinus Nijhoff, Dordrecht, The Netherlands.

Leonard, F. C., I. Stienezen, and K. J. O'Farrell. 1998. Overcrowding at the feeding area and effects on behavior and claw health in Friesian heifers. Pages 40-41 in Proc. 10th Int. Symp. Lameness in Ruminants, Lucerne, Switzerland.

Leonardi, C., and L. E. Armentano. 2003. Effect of quantity, quality, and length of alfalfa hay on selective consumption by dairy cows. J. Dairy Sci. 86:557-564.

Menzi, W., Jr., and L. E. Chase. 1994. Feeding behavior of cows housed in free stall barns. Pages 829-831 in Dairy Systems for the 21st Century. Am. Soc. Agric. Eng., St. Joseph, MI.

Mendl, M., A. J. Zanella, and D. M. Broom. 1992. Physiological and reproductive correlates of behavioural strategies in female domestic pigs. Anim. Behav. 44:1107-1121.

Olofsson, J. 1999. Competition for total mixed diets fed for ad libitum intake using one or four cows per feeding station. J. Dairy Sci. 82:69-79.

SAS Institute. 1999. SAS User's Guide. SAS Institute Inc., Cary, NC. 